\title{
O Adoecer Psíquico do Desempregado
}

Este artigo discute como as relações de trabalho influenciam os modos de subjetivação e quais suas conseqüências frente ao desemprego estrutural, considerando que a atribuição moral da categoria de trabalhador permanece inalterada apesar das atuais modificações sociais. Debate também as formações discursivas que perpassam a prática dos psicólogos e quais suas repercussōes na discussão de programas de saúde.

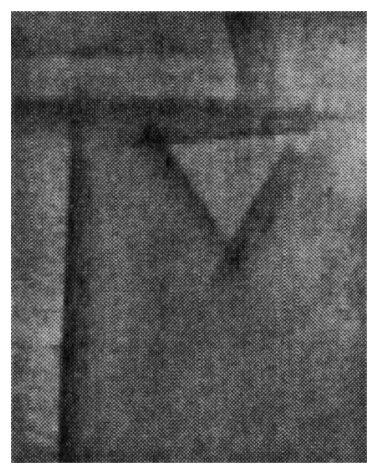

\section{Luciana Fim} Wickert Estudante de Psicologia Unisinos/RS

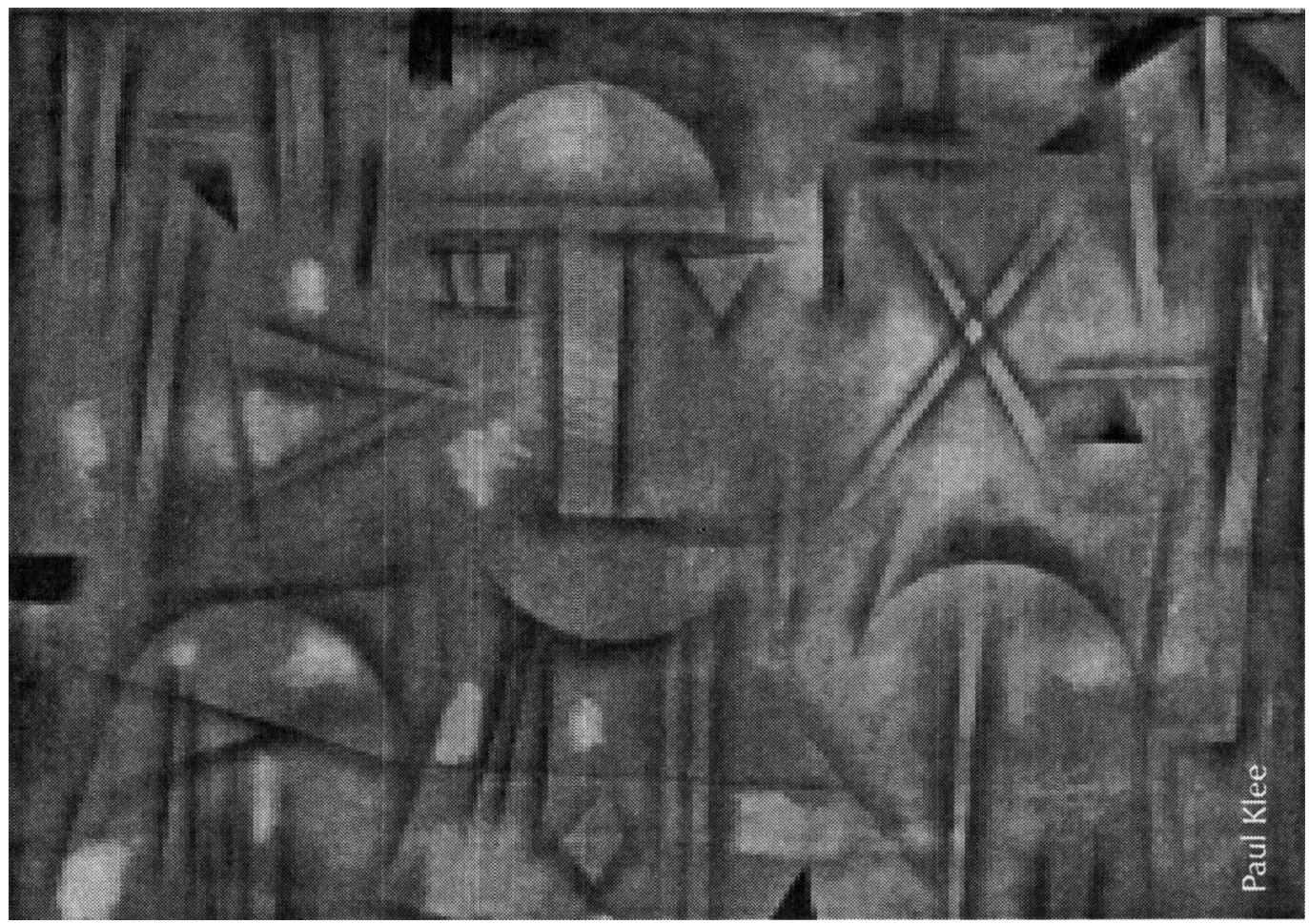

Este artigo tem como objetivo discutir como as relaçóes de trabalho influenciam os modos de subjetivaçáo e quais as conseqüências destes, enfocando questóes centrais da atualidade como o desemprego estrutural, o sofrimento psíquico dos desempregados e as formaçōes discursivas que perpassam e pautam a prática dos diferentes fazeres da Psicologia.

Primeiramente, se fará uma análise histórica, discutindo como, conjuntamente com o advento do Capitalismo, inicia-se a exaltação do trabalho com base de sustentação no campo das idéias. Para tanto, pontuar-se-á as modificaçōes ideológicas e os mecanismos de controle social, abordando como estes determinam a inserçăo social, através da associação ideológica trabalho/honestidade $\mathrm{e}$ da atrelagem dos conceitos de emprego e trabalho.

A seguir, discute-se que, apesar das modificações no mundo do trabalho e da realidade de desemprego estrutural, a atribuição moral da categoria de trabalhador assalariado permanece inalterada, ocasionando sofrimento psíquico àqueles que não conseguem inserir-se no mercado de trabalho. 
Por fim, propōe-se um debate sobre as formaçōes discursivas que perpassam a prática dos profissionais de Psicologia e quais as conseqüências destas para a discussão da realidade de desemprego estrutural e sofrimento psíquico dos trabalhadores, visto que entende-se que promoção de saúde envolve posicionamento político e luta por cidadania.

\section{Exaltação do Trabalho: Uma Construção Secular (Burguesa)}

Qual o papel que o trabalho ocupa nas nossas vidas? $\mathrm{O}$ que é ser um trabalhador? E quando nâo o somos? Quais as implicaçōes deste nãoser? Por que existe uma tendência a associarmos trabalho a emprego, apesar destes conceitos não serem coincidentes? Estas são algumas questōes abordadas ao longo deste artigo, que centra-se nos tópicos do desemprego, do sofrimento psíquico e dos papéis desempenhados pela Psicologia. A necessidade de discussáo sobre tal tema nasce das modificaçōes sociais que provoca $o$ desemprego estrutural e do debate teórico que evidencia o papel do trabalho na subjetividade e na contemporaneidade.

De que papel estamos falando? Nota-se que o advento do Capitalismo gerou, ao longo dos séculos, no campo ideológico, uma valorização moral da condição de trabalhador. Assim, apesar da centralidade ou descentralidade da categoria trabalho estar presente no debate atual, a atribuição moral da categoria de trabalhador assalariado permanece inalterada, ocasionando uma conseqüente desvalorização dos indivíduos que não se encontram nesta posiçâao (Forrester, 1997; Castel, 1998).

Se pensarmos no aumento do número de pessoas sem emprego e sem trabalho, temos como questāo crucial os impactos sociais e psicológicos causados por estas condiçōes. Já que conforme Seligmann-Silva "o trabalho (...) tanto poderá fortalecer a saúde mental quanto levar a distúrbios que se expressarăo coletivamente em termos psicossociais e/ou individuais, em manifestações psicossomáticas ou psiquiátricas" (1994, p.46), em suma, a sofrimento psíquico.
O trabalho nem sempre teve a conotação de valorização atual. Na Grécia Antiga, por exemplo, trabalhar não era nenhuma honra, bem pelo contrário, "... para os gregos, como observou Nietzsche (...) tanto o trabalho quanto a escravidão eram uma desgraça necessária, um motivo de vergonha, como se fossem a um só tempo uma desgraça e uma necessidade" (Finley apud Carmo, 1992, p.18), por este motivo era designado aos escravose aos sujeitos livres não-cidadāos.

Talvez esta razāo histórica explique a origem da palavra trabalho, que nos remete ao latim tripalium, instrumento formado por três estacas utilizadas para manter presos bois e animais difíceis de ferrar, ou ainda, em latim vulgar "pena ou servidão do homem à natureza" (Carmo, 1992, p.16). Nada muito digno, diríamos.

Têm-se claro que a exaltaçāo do trabalho nasce com a desenvolvimento do Capitalismo. Como na Idade Média, o trabalho realizado pelos servos não visava a produtividade, mas sim a subsistência do feudo, não existia uma preocupação com a acumulação de produção. Fato que se modifica quando "entra em cena o comerciante" (Carmo, 1992; Huberman, 1986). Enquanto no feudalismo a riqueza estava calcada na terra, com o desenvolvimento do comércio, existe uma transposição para o dinheiro. A acumulaçāo de riqueza passava a se dar pela moeda. Mas como acumulá-la?

A resposta é simples, apesar de cruel: pela exploração da mão-de-obra que provinha do campo. Com a implosão do Feudalismo, milhares de pessoas migraram para as cidades em busca de sobrevivência. A cidade, no imaginário coletivo, representava oportunidades de troca de classe e de uma nova vida. Entretanto, lá chegavam sem ter o que oferecer a não ser a força de seus braços.

A produtividade dos ex-camponeses era imperiosa para a acumulaçāo de capital. Para tanto, fez-se necessário uma mutaçăo ideológica, visto que o trabalho do povo que era considerado como uma porta de acesso aos Céus pela Igreja Católica, năo poderia ser concomitante com a prática do lucro e da usura, condenada por esta. Diante desta 
realidade, a burguesia incípiente, através da ética protestante que reavalia a posição cristā, legitimando o principio da obtenção do lucro, passa a incutir sua ideologia pela via religiosa. Pelo protestantismo, o trabalho passa a ser a finalidade de vida, um caminho a Deus. A Reforma Protestante constituiu, na sua essência, a primeira batalha da burguesia contra o feudalismo, visto que os interesses burgueses iam de encontro a manutençäo do sistema feudal defendida pela Igreja Católica (Huberman, 1986).

Mas, "dotar a sociedade de um novo ideal é uma questào que exige longo tempo; assim, enquanto fosse possivel usar a terra ou fazer artesanato, ninguém iria querer traba/har para outrem, submetendo-se a um salário irrisório e a todo tipo de opressão" (Carmo, 1992, p.30), pois alguém só "era um assalariado quando não era nada e nada tinha para trocar, exceto a

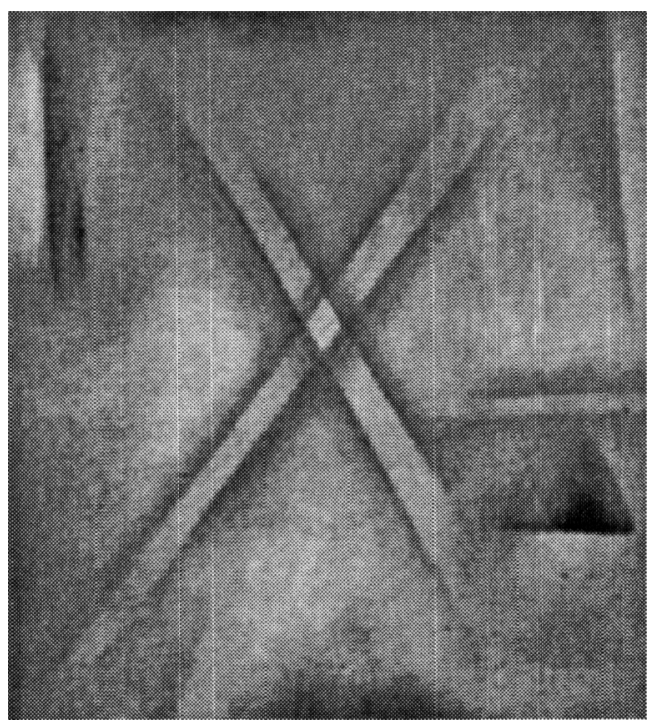

força de seus braços" (Castel, 1998, p.21). A soluçāo encontrada para o impasse social, sustentado pela ideologia, até então, dominante, foi a imposiçāo de leis que forçassem as pessoas livres a trabalhar, utilizando-se o sutil argumento de que eram vadias (Carmo, 1992). Argumento nâo tão sutil assim, afinal marcas de ferretes aos que infringiam às leis foram práticas comuns nesta época (Foucault, 1987). Aqui começa a associaçāo ideológica trabalho/honestidade $e$ a constituição do sujeito moderno.
Tal associação se deu por umà sociedade disciplinar, que acarretou em processos de individualização crescentes e marcantes na atualidade. $O$ sujeito até a ldade Média tinha seu lugar social garantido por mecanismos histórico-rituais. Com o Capitalismo e com a rede de saberes que se instaura junto a este, a individualizaçăo passa a ser produzida por mecanismos cientifico-disciplinares, "fazendo com que a individualidade do homem memorável seja substituida pela individualidade do homem calculável" (Fonseca, 1995, p.71). Entendendo que os modos de subjetivação atuais săo resultados das prăticas sociais e das relaçōes de poder formadoras de domínios de saber, visto que os sujeitos não sāo ahistóricos, constituindo-se, portanto, dentro destas relaçōes (Foucault apud Fonseca, 1995), percebe-se o motivo pelo qual o trabalho passa a se constituir como uma via de subjetivaçăo. Afinal a disciplina social pauta o mesmo como um valor essencial para a inserção social. Quem não trabalha, não produz, então, é dispensável ao sistema. Assim a disciplinarização da sociedade tem como seu maior efeito, a produçăo de uma individualidade adequada às exigências de acumulaçâo e gestão útil dos homens (Fonseca, 1995).

\section{Porta/Locação Social?}

O trabalho que antes era realizado em prol da comunidade, quer por subsistência ou estratificação social, passa a ser, por mecanismos científico-disciplinares, porta/ locação social. Porta/locação? Sim, o trabalho passa a ser a via de acesso para o lugar social, pois o sujeito ś tem o reconhecimento de sua existência, caso produza. Entretanto, quando já não é mais produtivo a sua locação deixa de existir, pois não tem mais como pagar o "aluguel" social.

Aqui denota-se a força do poder disciplinar...

"...um poder que, em vez de se apropriar e de retirar, tem como função maior 'adestrar'; ou sem dúvida adestrar para retirar e se apropriar ainda mais e melhor. (..) A disciplina 'fabrica' indivíduos; ela é a técnica especifica de um poder que toma os individuos ao mesmo tempo como objetos como instrumentos de seu exercício." (Foucault, 1987, p.143) 
Insere no sujeito a obrigação de ser algo já imposto. Entretanto a sutileza deste poder é tanta, por se dar sobre a vida cotidiana, impondo uma lei de verdade que deve ser reconhecida por todos, que faz com que o indivíduo não perceba sua sujeição (Foucault, 1988).

Desta forma, o sujeito que antes tinha o seu lugar na sociedade garantido pela tradiçăo, agora necessita do emprego para obtê-lo, visto que ele só é merecedor de respeito e reconhecimento se desempenhar funções necessárias ao fluxo do Capitalismo. A disciplina capitalista impôs, e ainda impóe, que só se é alguém quando se é um trabalhador ou um explorador do trabalho de outrem. Assim, "deformado sob a forma perversa de 'emprego', o trabalho funda a civilização ocidental" (Forrester, 1997, p.7).

Durante certo tempo, esta locação social se sustentou, pois existia um mercado sedento de māo-de-obra. $O$ trabalhador nem precisava ser qualificado, desde que se adaptasse ao modelo de organização do trabalho vigente. No sistema taylorista, por exemplo, precisava somente ter capacidade física de produçăo. Aliás, Taylor manifestava desprezo por qualquer participaçāo mental dos trabalhadores nas tarefas que julgava ser totalmente manuais e passiveis de parcelamento (Seligmann-Silva, 1994).

Entretanto, com o desenvolvimento tecnológico, milhares de vagas se fecharam e milhares se viram sem emprego. Se a locação social se dá pelo trabalho, deformado sob a forma perversa do emprego' como fica a subjetivação daquele que encontra-se com uma realidade que impede a inserção social? É importante salientarmos que năo se trata de uma crise provisória e sim de uma implosăo geral (Forrester, 1997). Assim nos ficam várias questôes: Quais as conseqüências deste fenômeno mundial? De que forma a vivência do desemprego implica em sofrimento psíquico? Como se dá a locaçăo social destes sujeitos? Existe?

Se nos reportarmos a exaltação do trabalho, certamente concordaremos com Carmo quando ele coloca que ... "estar desempregado não é estar com tempo livre para o lazer: os momentos de tensão, o sentimento de fracasso, de exclusăo social, e a sensação de ser facilmente descartável afetam profundamente o desempregado. Em uma

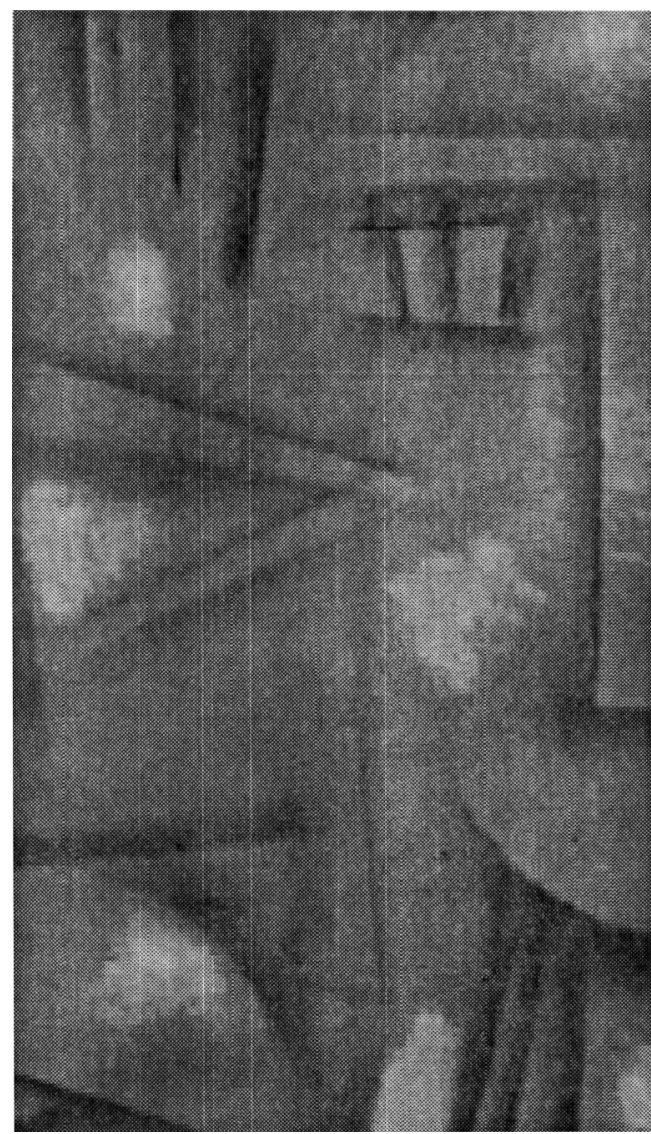

sociedade onde a participaçāo na abundância e o sucesso profissional são aspectos essenciais para a integração social, o fato de encontrarse sem trabalho constitui sentimento grave de derrota." (Carmo, 1992, p.13)

Derrota esta que causa vergonha individual, "porque cada um então se crê (é encorajado a crer-se) dono falido de seu próprio destino, quando nāo passou de um número colocado pelo acaso numa estatística" (Forrester, 1997, p. 10). Será um fracasso individual ou coletivo?

Castel (1998) aborda o tema dos "inempregáveis" ou supranumerários, indivíduos que são supérfluos à sociedade, visto que não existe emprego/lugar social para estes sujeitos. Ocorre, entăo, com estes o que autor chama de desfiliação social, termo
1. Ver referêncla bibliográfica anterior. 
utilizado no sentido de invalidez e não pertencimento grupal. Tal situação pode atingir a noção de identidade de trabalhador concebida por Costa (apud Tittoni \& Nardi, 1996) que compreende o trabalho como traço identificatório estruturador da identidade psicológica. Sendo assim, a vivência de desemprego acarreta num rompimento dos traços identificatórios estruturantes da identidade do trabalhador que, quando não substituídos por outras formas de exercícios da subjetividade, se traduz em sofrimento psíquico (Tittoni \& Nardi, 1996).

A desfiliação não afeta somente aqueles que não trabalham, mas pelo efeito bumerangue toda a sociedade. E é só por este motivo que encontramos alguma movimentação social em favor daqueles que não têm lugar/valorização social (Castel, 1998).

\section{Modificaçōes no Mundo do Trabalho}

Os princípios tayloristas e fordistas implantados neste século modificaram profundamente a organização do trabalho,

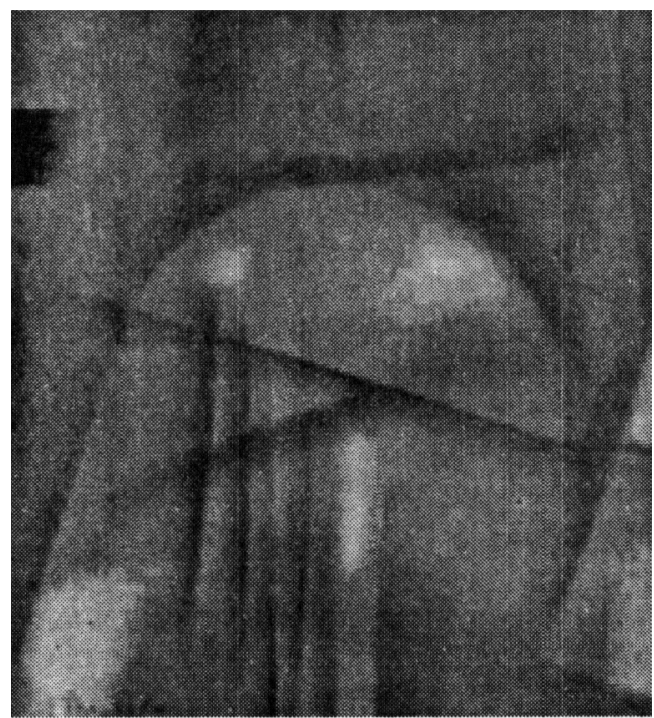

sendo que tais mudanças aliadas às transformaçōes ocorridas no maquinário industrial, repercutiram em alteraçōes no mecanismo de produção de mais-valia (Leite, 1994).

A década de 1980, como discute Antunes (1995), é marcada por transformaçőes no mundo do trabalho, tanto nas formas de inserção na estrutura produtiva, quanto nas formas de representaçăo sindical e política, sendo que estas afetaram a forma de ser, ou melhor dizendo, a subjetividade da "classeque-vive-do-trabalho". "Novos processos de trabalho emergem, onde o cronómetro e a produção em série e de massa são 'substituidos' pela flexibilização da produção, pela 'especializaçāo flexível', por novos padrōes de busca de produtividade, por novas formas de adequação da produção à lógica do mercado" (Antunes, 1995, p.16).

Tais modificaçōes ocasionaram um processo de reestruturação produtiva, que tem "...criado uma série de demandas que provocam transformaçōes nas formas de organizaçāo do trabalho"(Nardi, Tittoni \& Bernardes, 1997, p.243). Entre elas, a necessidade de um novo modelo de trabalhador, capaz de lidar com tecnologias e processos mais flexibilizados. Reforçando-se assim a idéia e a exigência de um trabalhador polivalente, participativo e flexível (Nardi, Tittoni \& Bernardes, 1997). Falar em flexibilidade é referir-se ao ajustamento do trabalhador moderno à sua tarefa e às demandas de mercado, ou seja, às exigências do Capital (Castel, 1998).

Veicula-se a necessidade de um novo tipo de trabalhador. Os meios de comunicação ensinam formas de se atualizar para conseguir um vaga. - Saiba um ou dois idiomas, aprenda a arte da computação, atualize-sel - Enfim, seja capaz, moderno (pós-moderno, que sabe?), avante no seu tempo. Como se o trabalhador conseguisse transformar-se na velocidade da luz. O pior é que se trata de um mensagem enganosa, pois nada garante que o indivíduo conseguirá um emprego se seguir as regras impostas pelas exigências de mercado. Pouco se veicula aos trabalhadores sobre a inexistência de vagas de trabalho, sobre o desemprego estrutural.

As empresas cada vez mais contratam jovens com qualificação superior aos cargos oferecidos, o que leva à desmotivação e ao desemprego em massa daqueles que realmente não estão qualificados. As políticas que enfatizam a qualificação como saída para o desemprego ou para evitá-lo estão ameaçadas pela lógica da contratação. Tentam disfarçar a realidade do desemprego estrutural, 
provocada pelo avanço tecnológico e conseqüiente substituiçāo da mão-de-obra por máquinas. Tais campanhas podem acarretar num aumento do nível de desempregados qualificados, sem contudo, modificar a situação de desemprego. Modifica o desempregado, não a sua situação (Castel, 1998). Os programas de qualificaçāo do trabalhador não discutem a lógica capitalista e nem seus efeitos, pois são frutos desta mesma lógica. Sendo assim, não săo suficientes e muito menos eficientes à redução do desemprego e do conseqüente sofrimento psíquico daqueles que vivenciam esta realidade.

Forrester (1997) alerta para o fato dos desempregados, vítima do desaparecimento de empregos, serem tratados e julgados pelos mesmos critérios utilizados na época em que os empregos eram abundantes. Os supranumerários são responsabilizados, então, por esta realidade social, através de campanhas de que precisam se atualizar. Trata-se de um processo de responsabilizar o trabalhador pela falta de emprego, de uma autoculpabilização do sujeito.

Estamos abordando aqui o conceito de emprego, entendendo por este, $o$ ato de alugar a capacidade de trabalho para outrem, em troca de certa quantia em dinheiro. Tal conceituação já pontua que existe diferença entre emprego e trabalho. Podemos definir este último...

"...como toda atividade realizada pelo homem civilizado que transforma a natureza pela inteligência. Há mediação entre o homem e a natureza: domando-a ele a seu desejo, o homem se transforma, se autoproduz e, ao se relacionar com outros homens, na realização da atividade, estabelece a base das relaçōes sociais". (Carmo, 1992, p.15)

Assim como Castel (1998) pensamos o trabalho como um suporte privilegiado de inscriçāo na estrutura social. Desta forma, quando o indivíduo encontra-se impedido de trabalhar, ação que na sociedade atual se visualiza através do emprego, se vê impedido de pertencer a um grupo social, fato que causa forte sofrimento psíquico. Como coloca Forrester "não é o desemprego em si que é nefasto, mas o sofrimento que ele gera ..." (1997, p.10).

\section{Psicologia do Trabalho x Saúde do Trabalhador}

Historicamente, a Psicologia veiculou suas atividades no campo do trabalho dentro de uma lógica de adaptação. Sua prática entrou no âmbito empresarial quando as idéias tayloristas já não mais garantiam a lucratividade, pois existiam "recursos humanos" a serem considerados e manejados. Desta forma, utilizava seu saber

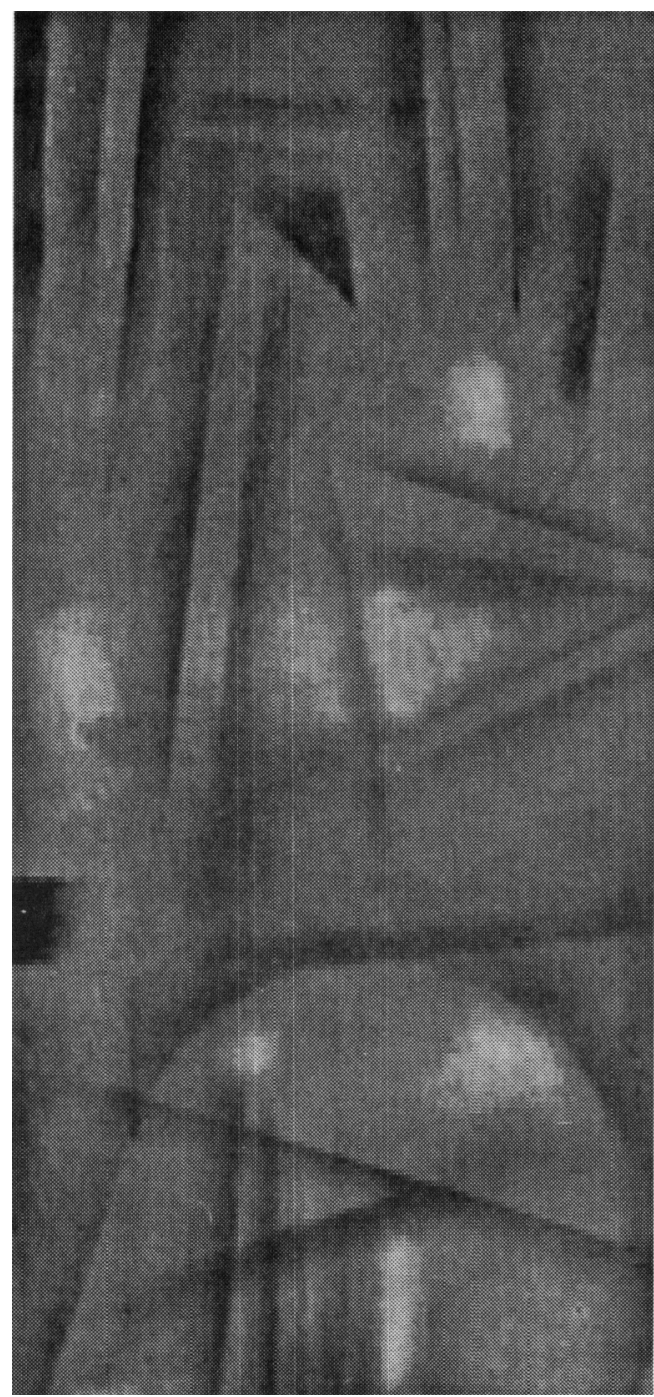

para buscar o melhor trabalhador, aquele que produzisse o methor trabalho e chegasse aos melhores resultados (Seligmann-Silva, 1994). Assim, a Psicologia entra no cenário do mundo do trabalho com um saber comprometido com a lógica do capital. 
Podemos pensar que tal posição de saber e, conseqüente, poder, constituiu o cerne de uma formação discursiva vinculada estritamente aos objetivos de lucro das empresas e a lógica de exploração capitalista. Entende-se por formaçāo discursiva a rede de enunciados, as regras implícitas ou explícitas, que perpassam e pautam a prática do profissional. Foucault esclarece que tem-se uma formaçăo discursiva...

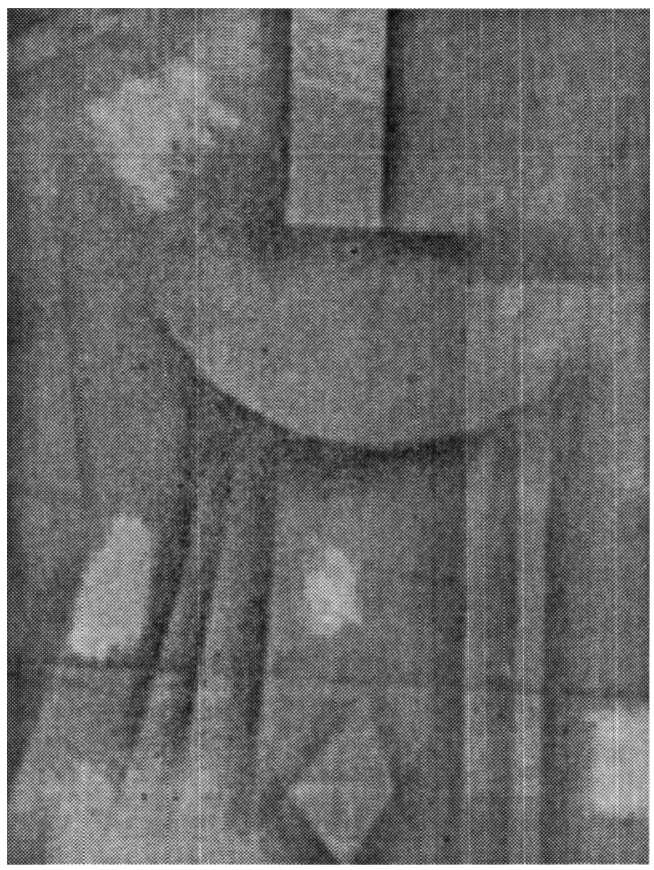

"no caso em que se puder descrever, entre um certo número de enunciados (...) e no caso em que entre os objetos, os tipos de enunciaçāo, os conceitos, as escolhas temáticas, se puder definir uma regularidade (uma ordem, correlações, posiçōes e funcionamentos, transformaçōes)". (1995, p.43)

Conforme Nardi "a delimitação das formações discursivas, dentro do conceito Foucaultiano, permite explicitar como o discurso, atuando como a funçăo de ser o representante de um saber, se configura para dar conta de um evento específico" (1996a, p.26). Ao analisarmos que a relação de saber-poder da Psicologia do Trabalho está pautada na lógica capitalista, pode-se entender que na sua formação discursiva "... a doença passa a ter como aspecto central, nāo o sofrimento do paciente, mas sim, a capacidade ou incapacidade para produzir" (Nardi, 1996a, p.80).
É importante pontuarmos que quando falamos em formaçōes discursivas também nos remetemos às marcas subjetivas ocasionadas pelos "modos de subjetivaçāo, ou seja, o modo como o sujeito deve relacionar-se com a regra a qual se vê obrigado a cumprir e também a forma como deve se reconhecer como ligado a essa obrigação" (Fonseca apud Nardi, Tittoni \& Bernardes, 1997, p.241).

Acreditamos ser possível discutir a existência de um paralelo entre as formaçōes discursivas da Psicologia do Trabalho ${ }^{2}$ e da Medicina do Trabalho, visto que na análise feita por Nardi, evidenciou-se que "... a Medicina do Trabalho assume uma função social e histórica de legitimar as prerrogativas do Capital em detrimento do Trabalho" (1996a, p.151). Diante disto, a relaçăo de saber/poder e os enunciados de racionalidade positiva de causaefeito, de capacitação e de culpabilizaçāo do indivíduo sâo bastante semelhantes. Tratamse, então, de estruturas discursivas que privilegiam o saber técnico em detrimento do saber do trabalhador. (Nardi, 1996b) Nas quais a saúde deste só é condição sine qua non ${ }^{3}$ no que tange a sua participação na produtividade capitalista. É a transformação do sujeito em objeto de exploraçāo, em maquinário diferenciado. Năo há espaço para a vivência do desejo e a possibilidade de traçar caminhos pessoais e originais em busca do bem-estar físico, psíquico e social, enfim, não existe campo para a saúde (Dejours, 1986).

Visto as semelhanças nas formaçōes discursivas, têm-se claro que a Psicologia do Trabalho, descrita acima, e a Medicina do Trabalho não apresentam projetos de inserção social; bem pelo contrário, suas funçôes centram-se na doença, na rotulação e na exclusão dos não-produtivos ao sistema. Sendo assim, a temática do sofrimento psíquico causado pelo desemprego năo the parecem pertinentes.

A discussão desta temática vem sendo realizada por trabalhadores de saúde coletiva que desenvolvem suas atividades calcados na formação discursiva da Saúde do Trabalhador, que se estrutura a partir de um conjunto de enunciados provenientes de diversas disciplinas, tais como: psicologia, saúde coletiva, saúde pública, medicina do trabalho, 
clínica médica, medicina social, sociologia, entre outras (Nardi, 1996a). Tal formação discursiva "... estabelece uma nova forma de compreensão das relaçōes entre saúde e trabalho e propōe uma nova prática de atenção à saúde dos trabalhadores..." (Nardi, 1996a, p.85-86). Considera o trabalhador como sujeito ativo do processo de saúde-doença $e$, portanto, torna indispensável a sua participação nas açōes de saúde.

Estes, que desenvolvem suas atividades dentro da formação discursiva da Saúde do Trabalhador, têm se preocupado e buscado formas de inserção/inscrição social para aqueles que encontram-se em situaçāo de desemprego, pois ser desempregado, não significa não ser trabalhador ${ }^{4}$. No entanto, tal busca nāo se dá de forma isolada e autocrática e sim em conjunto com os trabalhadores, pois o saber destes é fundamental na construção de um novo conceito de sociedade.

Assim, a discussão sobre trabalho e saúde mental iniciada de forma mais sistematizada no Brasil na década de oitenta, época do Movimento pela Reforma Sanitária, que traz em seu ideário os princípios da Saúde do Trabalhador, rompe com o discurso excludente das formaçōes discursivas vinculadas ao lucro, ao propor uma nova prática de atenção à saúde, ao colocar "... a saúde dos trabalhadores como principal objeto, ao invés do julgamento da aptidão para o trabalho" e como esta só é possível se o sujeito puder traçar seu próprio caminho, este se faz totalmente indispensável no processo. Desta forma, a prática imbutida nesta formação discursiva, denominada Saúde do Trabalhador, alia-se ao saber dos trabalhadores na busca de novas formas de compreensão das relações saúde/trabalho (Tittoni \& Nardi, 1995; Nardi, 1996a, p.90).

Dentro desta concepção de promoção de saúde, a interdisciplinariedade tem papel marcante, visto que nenhuma disciplina consegue abarcar o ser humano na sua totalidade. É necessário uma composição de saberes para que se promova um novo fazer. A Psicologia pode escolher de que lado está. Como coloca Rodrigues “...o psicólogo do trabalho já foi apelidado o 'obo mau' da Psicologia" (1997, p.342). Isso não foi à toa.
Promoção de saúde envolve posicionamento político e luta por cidadania. Desta forma, acreditamos que somente um trabalho que privilegie as contribuições conceituais oriundas do campo da Saúde do Trabalhador pode nos auxiliar no entendimento, na discussāo e no agenciamento de novas formas de inserção social daqueles que padecem de sofrimento psíquico ocasionado pela ausência de trabalho por motivo de desemprego.

\section{Considerações Finais}

As modificaçōes dos processos produtivos acarretaram alteraçōes nos mecanismos de produçāo de mais-valia e desemprego

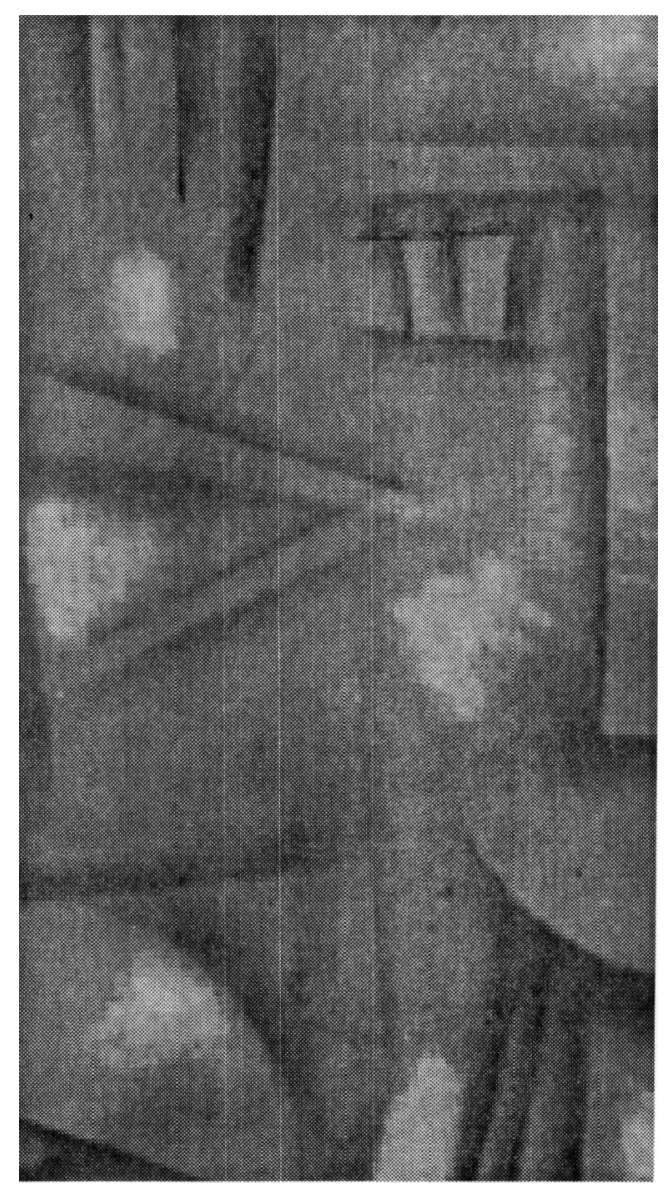

estrutural. Entendendo que estas repercutem nos processos de subjetivaçâo dos trabalhadores, visto que o trabatho é uma via de subjetivação e inserção social, nos fica a dúvida de quais são os impactos sociais e psicológicos decorrentes deste novo quadro societário.
4-Aliás, nâo existe prefixo ou suflxo, na Lingua Portuguesa. que anule a condicáo de trabalhador 
Discussões teórico-práticas (Seligmann-Silva, 1994; Forrester, 1997; Castel, 1998) apontam significativo sofrimento psíquico daqueles que se vêem desfiliados socialmente por motivo de desemprego, sendo tal sofrimento conseqüencia da atrelagem moral das concepções de trabalho, honestidade e valorização social, que encerram no ato de trabalhar as vias de inserção/inscriçăo social. Para a minimizaçāo deste sofrimento, faz-se necessário construírmos, coletivamente, novas formas de subjetivação e inserção/inscrição social, escapando da ótica individualizante, pois enquanto a problemática do desemprego for encarada dentro desta lógica, não haverá mudança social.

Para tanto, cabe a nós, enquanto profissionais de saúde e cidadãos, debatermos acerca da construção de tecnologias que possibilitem novas formas de inscrição/inserção social e a minimização do sofrimento psíquico. Certamente, trata-se de uma construção, de um novo fazer, onde a discussāo coletiva é a única alternativa.

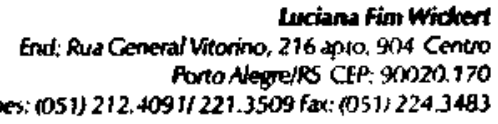

E-madi: Iuwickertghomailicom

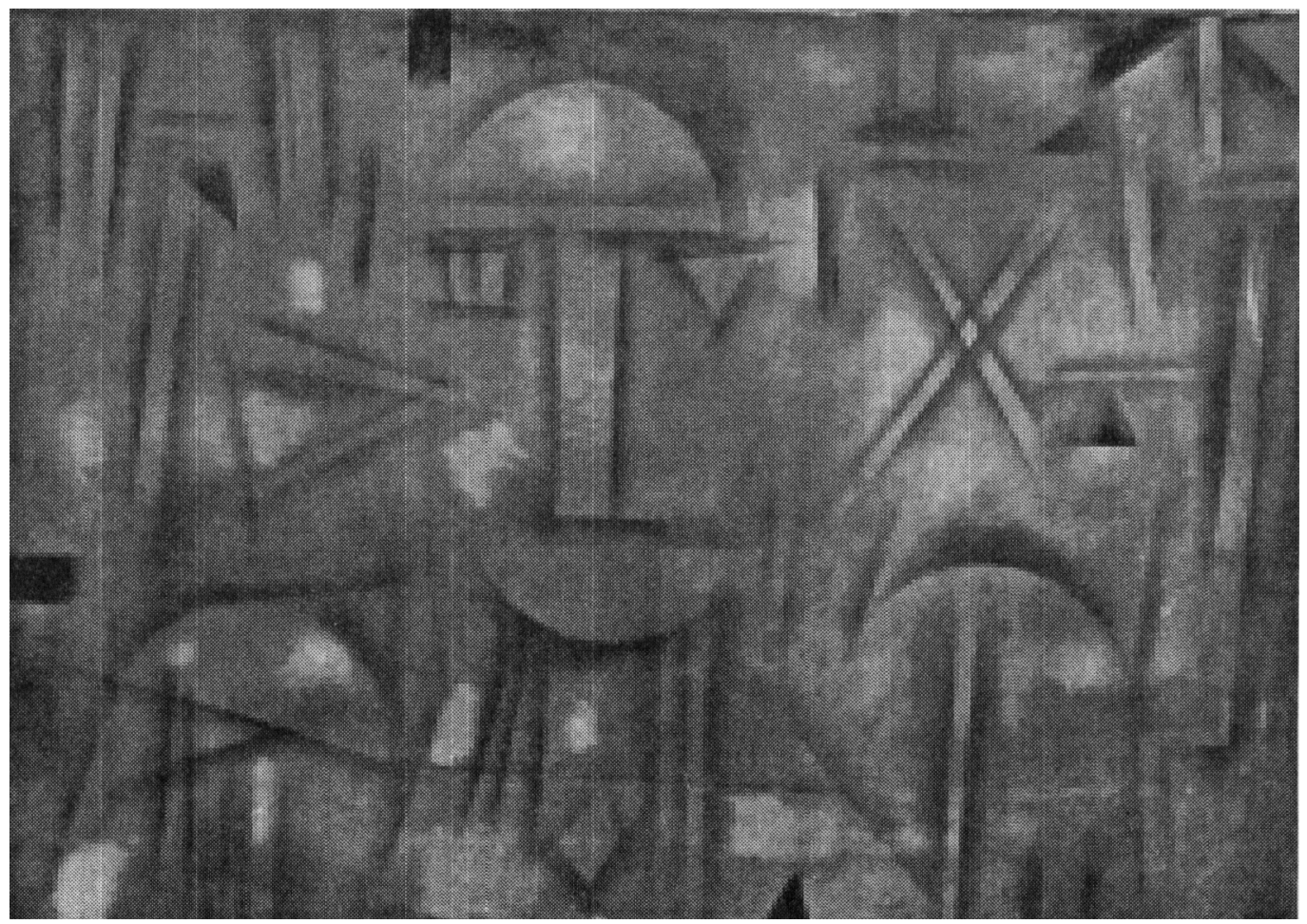


Antunes, R. (1995) Adeus do Trabatho?: ensaio sobre as metamorfosese a centralidade do mundo do trabaiho. Sáo Paulo : Cortez; Campinas, SP : Editora da Universidade Fstadual de Campinas.

Carmo, P. S. do, \{1992\}, A ideologia do trabatho. Sāo Paulo: Moderna.

Castel, R. (1998). As metamortoses da questāo social: uma crónica do salário. Petrópolis : Vozes.

Dejours, C. (1986).Por um nowo corceito de saúde. Revista Brasileira de Saúde Ocupacional, . 14, n. 54, pp.7-11.

Fonseca, M.A. (1995).Michel Foucault ea Constituiçào do Sujeito. Sào Paulo: Educ

Forrester, V. (1997) .O horror econốmico. Sào Paulo : Ediţora da Universidade Estadual Paulista.

Foucault, M. (1985) A Arqueologia do Saber. Traduçăo de Luiz Felipe Baeta Neves. 4 ed. Rio de Janeiro : Forense Universitáría.

Foucault, M. (1987). Vigiar e Punir: nascimento da prisảo. Traduçăo de Raque! Ramaihete. Petrópolis : Vozes.

Foucault, M. (1988). El sujeto y el poder. Revista Mexicana de Sociologia. Año L, n.3. Jul/Set, pp.3-20.

Huberman, L. (1986). História da Riqueza do Homem. 2 1 ect. Rio de laneíro : Afiliada.

Leite, M. de P. (1994), O futuro do trabalho. \$âo Paulo : Seritta.
Nardi, H. C. (1996a) Medicina do Trabatho e Saúde do Trabalhador: - Conltito Capital/Trabalho e a Relaçào Médico-Paciente. Dissertação de Mestrado em Sociologia, Universidade Federal do Rio Grande do Suł, Instituto de filosofia e Ciências Humanas, Programa de Pós-Craduação em Sociologia, Porto Alegre.

Nardi, H. C. (1996b) Trabalho e Doença: Disputas e Paradoxos do Social e do Inodividual. In: Educaçâo, Subjetividade e Atoder. v. 3 (marf jul 1996b) Porto Alegre : Núcleo de Estudos sobre Subjetividade, Poder e Educaçáo, Programa de Pós-Graduação em Eduçaçâo da UFRCS; fjui : Editora Unijuí, PP-67-74.

Nardi, H.; Tittoni, J. \& Bernardes, J. (1997) Subjetividade e Trabaikn. Em Cattani, A . D, forg) Trabalho e Tecnologia: Dicionário Critico. Porto Alegre : Vozes, pp. 240-46.

Rodrigues, H. de B. C. (1997) Compreensăo e Crítica da Psicologia do Trabalho: Relatos e Recontes sabre formaçāo em Saúde Mental do Trabalhador. Em Silva Filho, 1. F, jardim, S. R. (org). A Danaçăo do Trabalho: organizaçāo do trabalho e sotrimento psíquico. Rio de Janeiro : Te Corá, pp.335-342.

Seligmann-5., E. (1994). Desgaste Mental no Trabaiho Dominante. Rio de Janeiro : Cortez-UFRJ.

Tittoni, 1.; Nardi, H. C. (1995) As Relaçōes Saber/Poder na Discussão sobre Subjetividade e Trabalho - um estudo com trabalhadores afastados do trabalho por adoecimento profissional. Em Cadernos de Sociologia. Programa de Pós-Graduaçāo em Sociologia. v.7. Porto Alegre : PPCSIUFRCS, pp. 151-166.
Referências bibliográficas 